\title{
Classical Approach to Management of Menopause: Extended Scientific Literature
}

\author{
Rahul Hajare* \\ Department of Health Research, Ministry of Health and Family Welfare, India
}

Submission: December 06, 2017; Published: January 23, 2018

"Corresponding author: Rahul Hajare, Formerly Post-Doctoral Fellow, Indian Council of Medical Research, Department of Health Research, Ministry of Health and Family Welfare, India, Tel: 011-26588590; Email: rahulhajare@rediffmail.com

\begin{abstract}
Menopause is a natural transition that consists of biological and psychological changes that occur for women. It is an understudied and underfunded research topic that has been traditionally treated with allopathic medicine with a fairly low level of success and does not address the most significant symptoms of menopause, which include anxiety, depression, vaginal dryness, hot flashes, and insomnia. Ayurvedic medicine has been shown in preliminary studies to address and treat specific symptoms of menopause. Some studies show a significant improvement in symptoms compared to that of allopathic medicine; however these studies need to be reproduced on a larger scale to influence the medical community that is not familiar with Ayurveda.
\end{abstract}

\section{Opinion}

At her first period a woman meets her wisdom. Through her menstruating years she learns her wisdom, and at menopause she becomes her wisdom. Native America proverb Menopause is difficult to understand and study that deals with the study of identification, structure, rate of growth and with known and unknown odd mechanics; Physician remark for outcome of therapy for menopause reveal the information about patient's related factors including medication adherence. Menopause is a biological event has brought some natural history of nature could illustrate the complexity in selecting a baseline. If any side effect is detected, it should be treated thoroughly.

\section{Introduction}

When did human culture start thinking of menopause as a disease rather than a natural phase to be valued in a woman's life? Having worked several hours in a science college, I am very concerned with the number of women who specifically ask about hormone imbalances. When I probe deeper to understand what has brought them to an Ayurvedic clinic, they routinely tell me their allopathic doctor has told them they are having panic attacks rather than notice the natural correlation with their age and symptoms coinciding with perimenopause. Several women I have asked have told me they are having complete hysterectomies due to the fact their periods were irregular during this perimenopause period and that they were also give antidepressants to curb the anxiety and mood swings that came with perimenopause. Those were the only options besides continuing on birth control, which comes with significant side effects particularly for women over 40. Feeling a deep compassion for these women and approaching perimenopause in my own life, I began with research mind researching therapy to manage menopausal symptoms. The vast amount of research that should exist on this topic is minimal. Allopathic and alternative therapy research was underwhelming at best, but optimistic for those integrative practitioners who are willing to focus on a significantly overlooked area of female medicine.

\section{Ayurvedic Approaches for Management of Menopause}

Ayurvedic medicine, despite not having many clinical studies with a large number of participants, has recently been given accolades due to its lack of side effects, low cost, and promising results [1-3]. In a recent review in Ayurvedic, An International Quarterly Journal of Research in Ayurveda, the herbs Ashokarishta (ASK), Ashwagandhachurna (ASW), and Praval Prishti (PP) were used to manage menopausal symptoms. It was directed by Central Council for Research in Ayurvedic Sciences as a randomized open clinical trial. There were a total of 52 patients who were registered in the study, out of which 51 patients who completed the study. Specialized rating scales like Kupperman Index Score as well as Menopause Rating Scale (MRS) and Menopause Specific Quality of Life (MENQOL) questionnaires were adopted for diagnostic as well as assessment criteria. All the selected patients were given ASK $(25 \mathrm{ml}$ twice daily with equal quantity of water, after food, orally), ASW (3g twice daily 
with milk, half an hour before food, orally) and PP (1 capsule of $250 \mathrm{mg}$ twice daily with milk, half an hour before food, orally) for 3 months. The study worked with the majority of women who were in a healthy BMI, did not have a history of depression, anxiety, or reproductive health issues. The majority of these women were vegetarian. This study was conducted in India where roughly $33 \%$ percent of the population is vegetarian versus $3 \%$ in the United States. This study is under consideration aim and statistical results in process. We would like to introduce this opinion article has novel research experience.

\section{Discussion}

Due to the difficulty in finding Ayurvedic studies that are large and focus on the topic of women's health; the Ayurvedic conclusions drawn from this literary analysis may seem unsubstantial. It is also worth noting that research that focuses on alternatives to allopathic medicine lump Chinese herbs together with Ayurvedic herbs or other medicinal plants, creating an unclear treatment plan that would never be prescribed by an Ayurvedic practitioner. Due to these limitations in research it is not clear to what degree Ayurvedic treatment may benefit women, although the smaller studies used in this literary analysis show a definite success rate that supersedes the benefits of allopathic treatment.

\section{Acknowledgment}

This study has been guided under the unparallel supervision and guidance of Hon'ble Dr. Ramesh Paranjape, Retired as Director \& Scientist 'G' National AIDS Research Institute, India. I express my sincere gratitude towards Sir for motivation and being great knowledge source for this work. I seek continuous support for my research career.

\section{References}

1. Best Practice \& Research (2009) Alternative treatments for the menopause. Clinical Obstetrics \& Gynecology 23(1): 151-161.

2. Royal College of Obstetricians and Gynaecologists (2010) Alternatives to HRT for the Management of Symptoms of the 111 Menopause. Scientific Impact Paper No. 6.

3. Jane Woyka (2016) Alternatives to hormone replacement therapy (HRT) (Sections 1 and 8). Post Reproductive Health NICE guideline-Menopause: diagnosis and management 22(2): 67-69.

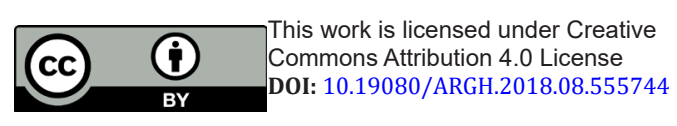

Your next submission with JuniperPublishers
will reach you the below assets
- Quality Editorial service
- Swift Peer Review
- Reprints availability
- E-prints Service
- Manuscript Podcast for convenient understanding
- Global attainment for your research
- Manuscript accessibility in different formats
( Pdf, E-pub, Full Text, audio)
- Unceasing customer service
Track the below URL for one-step submission
https://juniperpublishers.com/online-submission.php

